\title{
Smoking during pregnancy was negatively associated with physical fitness in childhood
}

\author{
Konstantinos D. Tambalis ${ }^{1}$, Stamatis Mourtakos ${ }^{1}$, Demosthenes D. Panagiotakos ${ }^{1}$, \\ Labros S. Sidossis ${ }^{1,2}$
}

'Department of Nutrition and Dietetics, Harokopio University, Athens, Greece

${ }^{2}$ Department of Kinesiology and Health, Rutgers University, New Brunswick, USA

Corresponding Author

Konstantinos D. Tambalis, Ph.D. Assistant Professor, Department of Nutrition and Dietetics,

School of Health Science \& Education, Harokopio University, Athens, Greece. 70 Eleftheriou Venizelou Ave, Athens 17671, Greece,

Tel.: +30 210 9549158, http://orcid.org/0000-0002-5817-9395, e-mail: dp425603@hua.gr

\section{Abstract}

Background: To explore the potential relationship of several prenatal predictors with physical fitness (PF) components among children.

Material and Methods: A random sample of 5,125 dyads children (8 to 9 years old) and their mothers was evaluated. Mothers were asked to provide information contained in their medical booklets and pregnancy ultrasound records. With the use of a standardized questionnaire, telephone interviews were carried out for the collection of maternal factors in order to assess the potential association between several prenatal factors (preterm birth, maternal age, parity before, mode of delivery, gestational diabetes, hypertensive disorders of pregnancy, alcohol consumption and smoking during pregnancy) and child's PF. Data from five $\mathrm{PF}$ tests were used to assess cardiorespiratory fitness (CRF), speed, and lower and upper body strength.

Results: Children born to mothers with adequate physical activity (PA) levels during pregnancy, parity before and higher education presented higher performances in PF components (all p-values $<0.05$ ) in childhood. Also, mother's smoking during pregnancy was unfavorably associated with CRF $(b=-0.04)$, lower body strength $(b=-0.02)$, upper body strength $(b=-0.02)$, and speed $(b=0.10)$, after adjusting for several covariates.

Conclusion: Among prenatal factors considered, parity before, educational level and PA and smoking during pregnancy had an important influence on PF in childhood.

Key words: prenatal factors, pregnancy, physical fitness, childhood

\section{Introduction}

Physical fitness (PF) is a dominant indicator of cardiovascular health in children and it is considered

that a sufficient level of PF in childhood is needed to carry forward advantageous biological and behavioral 
effects into later life, in a dose-response fashion ${ }^{1,2}$. In contrast, low PF in childhood is linked to risk factors such as obesity, hyperlipidaemia and hypertension ${ }^{2}$. $\mathrm{PF}$ is, at least in part, genetically determined, and perinatal factors may reinforce or attenuate this predetermined PF level ${ }^{3}$. Scientific evidences suggest that risk factors of several diseases originates from fetal life, and markers of fetal life conditions, such as maternal Body Mass Index (BMI) have been linked with adult coronary heart disease, hypertension and diabetes mellitus ${ }^{4,5}$. Furthermore, it is considered that maternal pregnancy conditions such as gestational diabetes ${ }^{6}$ hypertension in pregnancy ${ }^{7-9}$, maternal smoking ${ }^{10-12}$ and alcohol consumption ${ }^{13}$ have been connected with adult coronary heart disease, hypertension, diabetes mellitus or their premorbid risk factors. Also, early maternal age at childbirth ${ }^{14,15}$ and preterm delivery ${ }^{16}$ may possibly enlarge the risk of developing chronic diseases at older ages, while, it is well-known that gestational length could play a crucial role on PF in childhood ${ }^{17}$. The exact mechanisms of this fetal "programming" stay behind almost unknown. Moreover, the hypothesis that PF programming act as mediating factor has not scientifically documented. A possible clarification for the progress of $\mathrm{PF}$ is via developmental programming ${ }^{18}$. For example, it is speculated that children with low birth weight, a factor that represents poor in utero circumstances, have reduced cardiorespiratory fitness (CRF) and muscular strength ${ }^{18,19}$. To clarify analytically these associations, the initial action would be to assess whether fetal life factors could predict these outcomes.

Therefore, in the current study, we explore whether there is an association between prenatal factors and PF components in childhood. Specifically, we investigate the potential associations between young maternal age, gestational length, hypertension, diabetes mellitus, smoking and alcohol consumption and other prenatal factors with CRF, muscular strength and speed, in a representative cohort of Greek children aged 8- to 9-years, taken into consideration several potential covariates.

\section{Materials and Methods \\ Study design}

Population-based data, derived from 10 national school-based health surveys, from a national database, following an official request to the Greek Ministry of Education. The national database included anthropometric data and information on age, gender, city and area, home address and telephone number, which were collected yearly, at the same time period (spring), from 1997 to 2007, with the exception of 2002, in almost all schools of Primary Education (roughly 85\%); schools that did not participate were from borderland areas, with small numbers of children. Thus, from 1997 to 2007, a total of 651,582 8 - to 9 -year-old children (51\% boys and $49 \%$ girls, over $95 \%$ of the total student population) participated in the study. Measurements were performed by two trained Physical Education (PE) teachers in each school. PE teachers followed a specific protocol taught in corresponding seminars held by the Greek General Secretariat of Sports. The same protocol was employed in all schools.

\section{Data extraction}

A sample of 5,500 children $(0.8 \%$ of the entire population) was randomly extracted from the database and their mothers were contacted by telephone. Random extraction was performed through statistical software. The number of 5,500 subjects was adequate to achieve statistical power greater or equal to $99 \%$ for evaluating a $0.10 \pm 0.05$ change in the regression coefficients at $5 \%$ significance level of two-sided tested hypotheses. The random sampling was stratified according to the region and place of living (e.g., rural/urban), according to the National Statistical Agency and equally distributed during the 
study period (ie, 500 mothers per year). The women that refused to participate in the study were 183 (3.3\%). The sample of mother-child dyads covered all geographical regions of Greece (eg, mainland Greece and the islands). The information of the proposed protocol was collected through telephone interviews based on the Computer Aided Telephone Interviews (CATI) method. In order to validate the process, 100 face-to-face interviews were conducted to check for discrepancies with the information collected by telephone. No such discrepancies were noted in any of the variables evaluated.

\section{Measurements}

All the necessary information was collected using a standardised questionnaire, named the Childhood Obesity Pregnancy Determinants (ChOPreD) questionnaire, designed and developed with the collaboration of the Harokopio University Department of Nutrition \& Dietetics and Department of Geography and the University of Texas Medical Branch Department of Internal Medicine. The ChOPreD questionnaire was tested and internally revised by study's investigators during a pilot study, which confirmed its construct validity. During data collection, the mothers were asked to provide information contained in their medical booklets and pregnancy ultrasound records (eg, body weight, height) and recall certain information (eg, physical activity levels, breastfeeding, smoking patterns, alcohol consumption, educational status, etc). Mothers in Greece have ultrasounds at the start of the pregnancy and several times during its progress and receive records of the results. Only mothers that had full set of records were included in the study, which finalized the sample of 5,125 mother-children dyads. The BMI data for the children at the age of 8 years was calculated based on data retrieved from the national database. The maternal pre-pregnancy BMI status and the BMI of the offspring at the age of 8-9 years old were calculated as the ratio of body weight to the square of height $\left(\mathrm{kg} / \mathrm{m}^{2}\right)$. Gestational Weight Gain was calculated based on the difference between the mother's body weight at the last and first visits, based on ultrasound records.

\section{Prenatal determinants}

Prenatal and neonatal data such as maternal age, nationality, pregnancy in vitro and parity before were extracted from medical booklets and pregnancy ultrasound records. Data recall relating to the perinatal period is very common in pregnancy-related studies $^{20}$. Specifically, mothers were asked whether their child was born on the projected birth date or, if not, how many days earlier or later. Preterm birth was determined as the birth of an infant child at fewer than 37 weeks' gestational age ${ }^{21}$. The number of births before or after the birth of the child taking part in the research was also required. The questionnaire also required clarification whether pregnancy was the result of an IVF (In Vitro Fertilization), as this may correlate with diseases or pregnancy abnormalities.

\section{Maternal pregnancy conditions}

Mothers were asked about probable abnormalities and diseases before and during pregnancy (preeclampsia - hypertension and proteinouria or eclampsia-preeclampsia plus convulsions), as well as any history of diabetes or hypertension and whether they had diabetes or hypertension during pregnancy. Moreover, they were asked if they took medication, if they were treated in a hospital or whether they had to stay in bed for any reason. Also, mothers were asked if they smoked during pregnancy, and if so, the number of cigarettes smoked daily. Moreover, if they consumed alcohol during pregnancy, they were asked what they consumed: a) beer/wine, b) whisky/gin and c) any other and how many glasses of alcohol they consumed per week as well as which, if any, narcotic drugs they took. 


\section{Fitness tests}

The Eurofit PF test battery was used to evaluate children PF levels, initially proposed by the Council of Europe and used systematically from many European countries ${ }^{22}$. Specifically, for the purposes of the current study, five fitness tests were administered by two trained PE professionals in each school: a) Vertical jump (VJ; jump from a squatting position at the start); b) Standing long jump (SLJ; jump as far as possible from a standing position at the start). Both of these tests assess lower body explosive power. Also administered were: c) Small ball throw (SBT; 1 $\mathrm{kg}$ with both hands in a standing position), to assess upper body explosive strength; d) 30-meter sprint $(30 \mathrm{mS}$; from a standing start), to evaluate speedand agility; and e) Multi-stage 20-meter shuttle run, (20mSRT), to estimate CRF. The 20mSRT test consists of measuring the number of laps completed by subjects running up and down between two lines, set 20 meters apart, at an initial speed of $8.5 \mathrm{~km} / \mathrm{h}$ which increases by $0.5 \mathrm{~km} / \mathrm{h}$ every minute, using a pre-recorded audio tape. The above widely-used five fitness tests were selected as being representative of explosive, anaerobic and aerobic performance. Repeat tests ( 2 trials) were allowed for the VJ, SLJ, SBT and $30 \mathrm{mS}$, with the best performance of each recorded. Students' performance in PF tests was evaluated based on the PF normative age- and sex-specific values for 8- to-10-year-old Greek boys and girls ${ }^{23}$. Particularly, for each of the five PF tests applied, a performance $\leq 25$ th percentile was considered as low, between the 25 th and 75 th as average and $\geq 75$ th as high.

\section{Study approval}

The study was approved by the Bioethics Committee of Harokopio University. Oral approval was obtained from all mothers who agreed to participate in the study and written. Informed consent was obtained from those participants who took part in the validation process of the study.

\section{Statistical Analysis}

Continuous variables were presented as mean values \pm standard deviations (SD) given that they were normally distributed (as examined by the use of histograms and P-P plots). Categorical variables were presented as frequencies. The chi-square test evaluated associations between the categorical variables and the Student's t test were applied to evaluate differences in mean values of normally distributed variables. In order to assess the relationships between perinatal factors (as continuous variables) with physical fitness tests performances we applied linear regression analysis taking into consideration several covariates (children's BMI, birth weight, and gestational weight gain and breastfeeding months). Prior to that, every possible effect modification between the proposed risk factors and the confounders was examined, but all interaction terms were not statistical significant ( $p$-values>0.05). Furthermore, aiming to assess the potential effect of maternal characteristics on PF tests performance (low vs. high/average) binary logistic regression analyses was implemented and OR with the corresponding 95\% CI was calculated, while controlling for confounding. The Hosmer and Lemeshow's goodness-of-fit test was calculated in order to evaluate the model's goodness-of-fit and residual analysis was implicated using the dbeta, the leverage, and Cook's distance D statistics in order to identify outliers and influential observations. All analyses were performed using the SPSS version 23.0 software for Windows (SPSS Inc., Chicago, IL, USA). Statistical significance level from two-sided hypotheses was set at the $5 \%$ level $(\mathrm{p} \leq 0.05)$

\section{Results}

A total of 192 (3.5\%) mothers had not full set of data, while, 183 (3.3\%) of mothers did not participate in the study. Table 1 presents parental and offspring characteristics of the study sample. Table 2 presents 
Table 1. Characteristics of the studied sample of parents and their offspring.

$\begin{array}{lc}\text { OFFSPRING CHARACTERISTICS } & \\ \text { Males, n (\%) } & 2686(52.4 \%) \\ \text { Females, n (\%) } & 2439(47.5 \%) \\ \text { Age (years) } & 8.5(0.5) \\ \text { Birth Weight, Kg } & 3.33(0.5) \\ \text { BMI at Birth, Kg/m2 } & 12.6(1.7) \\ \text { BMI at Age } 8 \text { years, Kg/m2 } & 17.6(3.0) \\ \text { Physical fitness components } & \\ \text { Vertical jump (cm) } & 22.4(6.6) \\ \text { Standing long jump (cm) } & 73.4(30.3) \\ \text { Small ball throw (m) } & 4.0(1.2) \\ \text { 30-meter sprint (s) } & 6.4(0.8) \\ \text { 20-meter shuttle run (laps) } & 3.5(2.1) \\ \text { MATERNAL CHARACTERISTICS } & \\ \text { Maternal Age at Pregnancy, (years) } & 27.9(4.8) \\ \text { Gestational age (weeks) } & 39.2(1.6) \\ \text { Pregnancy in vitro, n (\%) } & 52(1.3) \\ \text { Bedtime during pregnancy, n (\%) } & 80(1.6) \\ \text { Parity before, n (\%) } & 2528(49.7) \\ \text { BMI in first visit, Kg/m2 } & 22.5(3.2) \\ \text { BMI in last visit, Kg/m2 } & 27.8(3.9) \\ \text { Gestational weight gain (GWG), Kg } & \\ & \end{array}$

maternal characteristics by PF test performances. The performances in all PF tests were higher in children of mothers with parity before as compared to children of mothers without parity before (all pvalues $<0.05$ ). Moreover, the performances in all PF tests were higher in children of mothers who did not smoked during pregnancy in comparison to children of mothers who smoked (all p-values $<0.05$ ). Table 3 presents the results of linear regression analysis showing the estimated change in mean performances of PF tests per maternal characteristics adjusted for children's BMI, birth weight, GWG and breastfeeding months. Specifically, the analysis showed that number

\section{MATERNAL CHARACTERISTICS}

Educational status

Basic $(\leq 6$ years $)(\%)$

23.4

Secondary $(\leq 12$ years) $(\%)$

44.4

Higher (> 12 years) $(\%)$

32.2

Physical activity levels

Never, n (\%)

$3303(64.5)$

Moderate, n (\%)

858 (16.7)

Sometimes/often, n (\%)

$966(15.8)$

Breastfeeding (months)

$3.2(4.0)$

Smoking during pregnancy, n (\%)

$588(11.5)$

Alcohol consumption, $\mathrm{n}(\%)$

Drugs during pregnancy, $\mathrm{n}(\%)$

$6(0.2)$

Alcohol consumption during pregnancy,

$476(9.3)$

Diabetes during pregnancy, n (\%)

97 (1.9)

Hypertension during pregnancy, $\mathrm{n}(\%)$

$118(2.3)$

\section{PARENTAL CHARACTERISTICS}

$\mathrm{BMI}, \mathrm{Kg} / \mathrm{m} 2$

$27.7(3.7)$

Educational status

Basic ( $\leq 6$ years) $(\%)$

31.8

Secondary $(\leq 12$ years) $(\%)$

40.8

Higher (> 12 years) $(\%)$ of births before, more days PA during pregnancy and higher educational level were positively associated with PF tests performances, while, smoking during pregnancy was negatively associated with PF tests performances (all p-values<0.05). For example, each cigarette increase in smoking during pregnancy was associated with a 0.04 stage decrease in childhood 20 -meter shuttle run test (95\% CI: $-0.08,-0.01$, $\mathrm{p}=0.021$ ).

Furthermore, binary logistic regression analysis was applied to evaluate the effect of several maternal characteristics on performances (average/high vs. low) in all PF tests (Table 4). The analysis revealed 
Table 2. Maternal characteristics by physical fitness tests components

\begin{tabular}{|c|c|c|c|c|c|}
\hline & & PHYSI & L FITNESS TE & & \\
\hline & $\begin{array}{l}\text { 20-METER } \\
\text { SHUTTLE RUN } \\
\text { (LAPS) }\end{array}$ & $\begin{array}{l}\text { VERTICAL JUMP } \\
\text { (CM) }\end{array}$ & $\begin{array}{l}\text { STANDING } \\
\text { LONG JUMP } \\
\text { CM) }\end{array}$ & $\begin{array}{l}\text { 30-METER } \\
\text { SPRINT (S) }\end{array}$ & $\begin{array}{l}\text { SMALL BAL } \\
\text { THROW (M }\end{array}$ \\
\hline MATERNAL CHARACTERI & & & & & \\
\hline Maternal age at childbirth & & & & & \\
\hline >35 years & $3.6 \pm 2.3$ & $22.5 \pm 8.3$ & $65.8 \pm 30.4$ & $6.4 \pm 0.7$ & $3.9 \pm 1.2$ \\
\hline$\leq 35$ years & $3.5 \pm 2.1$ & $22.4 \pm 9.3$ & $67.8 \pm 29.0$ & $6.4 \pm 0.7$ & $4.0 \pm 1.2$ \\
\hline$\leq 18$ years & $3.6 \pm 2.2$ & $21.8 \pm 8.7$ & $69.3 \pm 28.7$ & $6.5 \pm 0.8$ & $3.8 \pm 1.3$ \\
\hline Gestational age & & & & & \\
\hline Term delivery $\geq 37 \mathrm{wk}$ & $3.5 \pm 2.2$ & $22.4 \pm 8.3$ & $73.4 \pm 29.8$ & $6.4 \pm 0.7$ & $4.0 \pm 1.1$ \\
\hline Preterm delivery $<37 \mathrm{wk}$ & $3.4 \pm 2.2$ & $22.2 \pm 8.4$ & $71.8 \pm 29.1$ & $6.4 \pm 0.7$ & $3.9 \pm 1.1$ \\
\hline Pregnancy in vitro & & & & & \\
\hline Yes & $3.6 \pm 2.5$ & $22.6 \pm 8.4$ & $68.0 \pm 26.1$ & $6.2 \pm 0.7$ & $3.8 \pm 1.5$ \\
\hline No & $3.6 \pm 2.2$ & $22.4 \pm 8.7$ & $70.4 \pm 30.0$ & $6.4 \pm 0.8$ & $4.0 \pm 1.2$ \\
\hline Parity before & & & & & \\
\hline None & $3.4 \pm 2.2$ & $22.1 \pm 8.1$ & $70.1 \pm 31.2$ & $6.6 \pm 0.7$ & $3.8 \pm 1.2$ \\
\hline One or more & $3.7 \pm 2.2^{*}$ & $22.8 \pm 8.5^{*}$ & $78.8 \pm 25.9$ & $6.3 \pm 0.8$ & $4.1 \pm 1.1$ \\
\hline Bedtime during pregnancy & & & & & \\
\hline Yes & $3.6 \pm 2.2$ & $22.2 \pm 8.4$ & $69.1 \pm 26.8$ & $6.4 \pm 0.8$ & $4.0 \pm 1.4$ \\
\hline No & $3.6 \pm 2.2$ & $22.8 \pm 8.5$ & $72.4 \pm 25.2$ & $6.3 \pm 0.8$ & $4.2 \pm 1.2$ \\
\hline Educational level & & & & & \\
\hline Basic, $\leq$ 6years & $3.5 \pm 2.2$ & $21.4 \pm 8.2$ & $71.3 \pm 29.8$ & $6.6 \pm 0.7$ & $3.6 \pm 1.1$ \\
\hline Secondary/High, $>6$ years & $3.9 \pm 2.2^{*}$ & $22.5 \pm 8.3^{*}$ & $75.6 \pm 29.1^{*}$ & $6.4 \pm 0.7^{*}$ & $4.0 \pm 1.1^{*}$ \\
\hline Physical activity during pre & & & & & \\
\hline Inadequate, $\leq 3 \mathrm{~d} / \mathrm{wk}$ & $3.4 \pm 2.1$ & $22.0 \pm 8.1$ & $72.1 \pm 29.9$ & $6.5 \pm 0.7$ & $4.0 \pm 1.1$ \\
\hline Adequate, $>3 \mathrm{~d} / \mathrm{wk}$ & $3.7 \pm 2.1^{*}$ & $22.8 \pm 7.5^{*}$ & $78.7 \pm 26.1^{*}$ & $6.2 \pm 0.7^{*}$ & $4.2 \pm 1.1$ \\
\hline Smoking during pregnancy & & & & & \\
\hline Yes & $3.3 \pm 2.2$ & $21.4 \pm 8.3$ & $72.2 \pm 29.1$ & $6.6 \pm 0.7$ & $3.9 \pm 1.1$ \\
\hline No & $3.7 \pm 2.2^{*}$ & $22.7 \pm 8.2^{*}$ & $76.7 \pm 31.5$ & $6.4 \pm 0.7$ & $4.3 \pm 1.2$ \\
\hline Alcohol consumption & & & & & \\
\hline Yes & $3.4 \pm 2.3$ & $22.1 \pm 8.7$ & $74.5 \pm 29.4$ & $6.4 \pm 0.7$ & $4.0 \pm 1.2$ \\
\hline No & $3.6 \pm 2.2$ & $22.4 \pm 8.1$ & $75.7 \pm 26.5$ & $6.4 \pm 0.7$ & $4.2 \pm 1.2$ \\
\hline Drugs during pregnancy & & & & & \\
\hline Yes & $2.8 \pm 2.2$ & $21.0 \pm 6.0$ & $64.7 \pm 39.5$ & $6.2 \pm 0.6$ & $2.6 \pm 0.5$ \\
\hline No & $3.6 \pm 2.2$ & $22.5 \pm 8.8$ & $73.7 \pm 30.5$ & $6.4 \pm 0.7$ & $4.0 \pm 1.2$ \\
\hline Hypertensive disorders & & & & & \\
\hline Yes & $3.5 \pm 2.2$ & $22.3 \pm 9.9$ & $70.1 \pm 26.9$ & $6.4 \pm 0.8$ & $4.0 \pm 1.1$ \\
\hline No & $3.6 \pm 2.2$ & $22.4 \pm 8.2$ & $73.8 \pm 29.2$ & $6.4 \pm 0.7$ & $4.1 \pm 1.2$ \\
\hline Gestational diabetes & & & & & \\
\hline Yes & $3.3 \pm 2.1$ & $21.7 \pm 8.8$ & $72.1 \pm 21.4$ & $6.5 \pm 0.7$ & $4.0 \pm 1.0$ \\
\hline No & $3.5 \pm 2.2$ & $22.4 \pm 8.3$ & $73.2 \pm 29.1$ & $6.4 \pm 0.7$ & $4.1 \pm 1.2$ \\
\hline
\end{tabular}

Values are presented as Means \pm SD. ${ }^{*} \mathrm{P}<0.05$ for differences between groups. 
Table 3. The relationship between maternal characteristics and child's physical fitness components at the age of 8 to 9 -years old

\begin{tabular}{|c|c|c|c|c|c|}
\hline \multirow[b]{3}{*}{$\begin{array}{l}\text { Maternal } \\
\text { characteristics }\end{array}$} & \multicolumn{5}{|c|}{ PHYSICAL FITNESS TESTS } \\
\hline & $\begin{array}{l}\text { 20-METER SHUTTLE } \\
\text { RUN (STAGES) }\end{array}$ & $\begin{array}{l}\text { VERTICAL JUMP } \\
\text { (CM) }\end{array}$ & $\begin{array}{l}\text { STANDING LONG } \\
\text { JUMP (CM) }\end{array}$ & $\begin{array}{l}\text { 30-METER } \\
\text { SPRINT (S) }\end{array}$ & $\begin{array}{l}\text { SMALL BALL } \\
\text { THROW (M) }\end{array}$ \\
\hline & b $(95 \% \mathrm{CI})$ & b $(95 \% \mathrm{CI})$ & b $(95 \%$ CI $)$ & b $(95 \%$ CI $)$ & b $(95 \%$ CI $)$ \\
\hline $\begin{array}{l}\text { Maternal age } \\
\text { (years) }\end{array}$ & $-0.02(-0.08,04)$ & $0.00(-0.02,0.02)$ & $0.01(-0.01,0.02)$ & $-0.02(-0.04,0.05)$ & $0.07(-0.04,0.19)$ \\
\hline Gestational age (weeks) & $0.02(-0.01,0.04)$ & $0.01(-0.01,0.01)$ & $0.00(-0.01,0.02)$ & $-0.02(-0.09,0.04)$ & $0.02(-0.02,0.06)$ \\
\hline $\begin{array}{l}\text { Parity before (number } \\
\text { of birth) }\end{array}$ & $0.05(0.01,0.11)^{*}$ & $0.61(0.18,1.24)^{*}$ & $0.98(0.45,1.54)^{*}$ & $-0.06(-0.09,-0.03)^{*}$ & $0.09(0.01,0.17)^{*}$ \\
\hline $\begin{array}{l}\text { Bedtime during } \\
\text { pregnancy (days) }\end{array}$ & $0.68(-1.38,2.74)$ & $0.01(-0.36,0,38)$ & $0.27(-0.16,0.70)$ & $2.67(-4.37,7.42)$ & $-0.32(-4.94,4.30)$ \\
\hline $\begin{array}{l}\text { Educational level (basic, } \\
\text { high, technological, } \\
\text { academic) }\end{array}$ & $0.02(0.003,0.04)^{*}$ & $0.05(0.01,0.09)^{*}$ & $0.09(0.01,0.20)^{*}$ & $-0.02(-0.04,-0.001)^{*}$ & $0.07(0.04,0.09)^{*}$ \\
\hline $\begin{array}{l}\text { Physical activity in } \\
\text { pregnancy (days/ week) }\end{array}$ & $0.02(0.004,0.03)^{*}$ & $0.05(0.02,0.08)^{*}$ & $0.04(0.02,0.06)^{*}$ & $-0.07(-0.10,-0.03)^{*}$ & $0.06(0.03,0.08)^{*}$ \\
\hline $\begin{array}{l}\text { Smoking in pregnancy } \\
\text { (number of cigarettes) }\end{array}$ & $-0.04(-0.08,-0.01)^{*}$ & $\begin{array}{c}-0.01(-0.02 \\
-0.01)^{*}\end{array}$ & $\begin{array}{c}-0.02(-0.04 \\
-0.01)^{*}\end{array}$ & $0.10(0.01,0.20)^{*}$ & $-0.02(-0.03,-0.01)^{*}$ \\
\hline $\begin{array}{l}\text { Alcohol consumption } \\
\text { (number of glasses) }\end{array}$ & $0.01(-0.01,0.02)$ & $0.01(-0.02,0.04)$ & $0.01(0.00,0.02)$ & $0.01(-0.03,0.04)$ & $0.02(-0.001,0.04)$ \\
\hline
\end{tabular}

Adjusted for children's Body Mass Index (8 to 9-y-old), birth weight, and gestational weight gain and breastfeeding months. *P-value for linear regression analysis $<0.05$.

that children of mothers with adequate PA during pregnancy had $20-70 \%$ increased odds for average/ high performances in PF tests in comparison with those of mothers with inadequate PA levels, after adjustment for GWG, birth weight, and breastfeeding months and children's BMI at 8 to 9-y-old. Also, children of mothers who did not smoking during pregnancy presented $20-50 \%$ increased odds for average/high performances in PF, than those of mothers who smoking.

\section{Discussion}

To the extent that we know the current study is among few aimed to consider the association of maternal characteristics on a wide range of $\mathrm{PF}$ tests performances in childhood. Results from this representative cohort revealed that (a) smoking during pregnancy was negatively associated with all PF components, (b) increased PA levels during pregnancy, parity before and maternal higher educational level were favorably associated with PF components, and (c) not smoking during pregnancy increased the odds of average/high performances (it can be considered a healthy fitness zone) in all PF components in childhood. The previous associations were remained statistically significant even after adjusting for several covariates.

In line with our results, a previous study by Hagnas et al, has shown that maternal smoking during pregnancy was associated with lower CRF among male adolescents ${ }^{24}$. Among many other potential adverse effects of maternal smoking on offspring health, it is considered that increases the risk for overweight/ obesity at the childhood and young adulthood, while 
Table 4. Results (OR, 95\%CI) from logistic regression models that used to evaluate the association of maternal characteristics on low performance in physical fitness components.

\begin{tabular}{|c|c|c|c|c|c|}
\hline & & & ISICAL FITNESS TE & & \\
\hline & $\begin{array}{c}\text { 20-METER SHUTTLE } \\
\text { RUN (LOW VS. } \\
\text { AVERAGE/HIGH) }\end{array}$ & $\begin{array}{c}\text { VERTICAL } \\
\text { JUMP (LOW VS. } \\
\text { AVERAGE/HIGH) }\end{array}$ & $\begin{array}{l}\text { STANDING LONG } \\
\text { JUMP (LOW VS. } \\
\text { AVERAGE/HIGH) }\end{array}$ & $\begin{array}{c}\text { 30-METER } \\
\text { SPRINT (LOW VS. } \\
\text { AVERAGE/HIGH) }\end{array}$ & $\begin{array}{c}\text { SMALL BALL } \\
\text { THROW (LOW VS. } \\
\text { AVERAGE/HIGH) }\end{array}$ \\
\hline $\begin{array}{l}\text { Maternal } \\
\text { characteristics }\end{array}$ & OR $(95 \%$ CI $)$ & OR $(95 \% \mathrm{CI})$ & OR $(95 \% \mathrm{CI})$ & OR $(95 \%$ CI $)$ & OR $(95 \% \mathrm{CI})$ \\
\hline $\begin{array}{l}\text { Maternal age (>35 } \\
\text { vs. } \leq 35 \text { years) }\end{array}$ & $1.00(0.74-1.35)$ & $0.88(0.69-1.32)$ & $1.09(0.68-1.58)$ & $1.02(0.77-1.36)$ & $1.17(0.80-1.65)$ \\
\hline $\begin{array}{l}\text { Gestational age } \\
\text { (term vs. preterm } \\
\text { delivery) }\end{array}$ & $0.88(0.76-1.02)$ & $1.00(0.88-1.14)$ & $1.08(0.91-1.30)$ & $0.89(0.70-1.10)$ & $1.04(0.89-1.20)$ \\
\hline $\begin{array}{l}\text { Pregnancy in vitro } \\
\text { (yes vs. no) }\end{array}$ & $1.22(0.62-2.40)$ & $0.87(0.46-1.63)$ & $1.21(0.89-1.64)$ & $0.98(0.78-1.37)$ & $1.28(0.58-2.40)$ \\
\hline $\begin{array}{l}\text { Parity before (none } \\
\text { vs. one or more) }\end{array}$ & $1.15(1.05-1.26)$ & $1.21(1.07-1.37)$ & 1.75 (1.47-2.09) & $1.32(1.15-1.51)$ & $1.22(1.07-1.40)$ \\
\hline $\begin{array}{l}\text { Bedtime during } \\
\text { pregnancy (yes vs. } \\
\text { no) }\end{array}$ & $0.64(0.30-1.34)$ & $0.85(0.50-1.44)$ & $1.30(0.70-2.13)$ & $1.10(0.57-2.02)$ & $1.18(0.53-1.94)$ \\
\hline $\begin{array}{l}\text { Educational } \\
\text { level (basic vs. } \\
\text { secondary/high) }\end{array}$ & $1.23(1.05-1.50)$ & $1.26(1.06-1.50)$ & $1.22(1.02-1.44)$ & 1.31 (1.08-1.58) & $1.77(1.45-2.02)$ \\
\hline $\begin{array}{l}\text { PA during } \\
\text { pregnancy } \\
\text { (inadequate vs. } \\
\text { adequate) }\end{array}$ & $1.20(1.02-1.39)$ & $1.29(1.03-1.60)$ & $1.70(1.12-2.57)$ & $1.50(1.05-2.14)$ & $1.50(1.08-2.01)$ \\
\hline $\begin{array}{l}\text { Smoking during } \\
\text { pregnancy (yes vs. } \\
\text { no) }\end{array}$ & $1.51(1.23-1.85)$ & $1.29(1.07-1.55)$ & $1.35(1.10-1.52)$ & $1.23(1.02-1.48)$ & 1.19 (1.01-1.39) \\
\hline $\begin{array}{l}\text { Alcohol } \\
\text { consumption (yes } \\
\text { vs. no) }\end{array}$ & $0.97(0.76-1.24)$ & $1.21(0.98-1.49)$ & $1.06(0.78-1.45)$ & $0.94(0.74-1.19)$ & $1.18(0.80-1.61)$ \\
\hline $\begin{array}{l}\text { Hypertensive } \\
\text { disorders (yes vs. } \\
\text { no) }\end{array}$ & $1.06(0.66-1.70)$ & $1.10(0.73-1.66)$ & $1.50(0.83-2.71)$ & $1.33(0.81-2.11)$ & $1.19(0.79-1.79)$ \\
\hline $\begin{array}{l}\text { Gestational diabetes } \\
\text { (yes vs. no) }\end{array}$ & $2.01(1.34-2.22)$ & $1.52(1.00-2.32)$ & $1.15(0.56-2.36)$ & $0.99(0.60-1.65)$ & $0.82(0.50-1.35)$ \\
\hline
\end{tabular}

Adjusted for children's Body Mass Index (8 to 9-y-old), birth weight, and gestational weight gain and breastfeeding months.

it is straightforwardly associated with higher fat mass $^{25,26}$. Moreover, it was speculated that maternal smoking is associated with lower birth weight ${ }^{26}$. Low birth weight, overweight and increased fat mass could be among underlying reasons for lower CRF among offspring exposed to maternal smoking. Furthermore, maternal smoking might has an adverse effect on pulmonary creation which leads to impaired lung function and decreased exercise capacity ${ }^{26}$.

In the current study we found a favorable asso- 
ciation between maternal PA during pregnancy and PF components among their offspring in childhood. To the best of our knowledge, there are no studies that have examined this association. According to a recent study by McMillan et al, PA during pregnancy can favorably influence neuromotor development, therefore leading to infants to be more adept at movement, and most likely to be more physically active $^{27}$. Specifically, the study proposed that the fetus' hearts most probably had sped up and synchronized with their mothers' during PA, enabling the infants to have the same heart benefits ${ }^{27}$.

Our results proposed a positive effect of maternal's education level on PF components. In accordance with previous findings, recent study speculated that offspring of mothers with higher education level presented increased PF in childhood ${ }^{28}$. Also, another study proposed that lower parental education associated with lower PF in adolescence ${ }^{29}$. Perhaps children from families with low socioeconomic status could be benefit from interventions targeted on PF stimulation and healthy dietary habits.

The association between parity before and PF has not been well examined. Our analysis revealed that children who had one or more older siblings presented better PF performances as compared to children who had not. Similarly, Lucovnik et al, reported that first-born children have lower PF in childhood $^{28}$. In contrast to previous findings, Barclay and Myrskyla, speculated the opposite, ie, better PF measurements in first-borns in early adulthood ${ }^{30}$. Nevertheless, it is significant to point out that the last study taken into consideration only males at a backdate time period (1965-1977) and it did not related to prenatal experience.

Even the associations we presented are modest; they have significant public health implications. They propose that the benefits prevention and optimal treatment of conditions such as PA, educational level and not smoking during pregnancy are pos- sible to prolong to offspring long-term health and to recognize at-risk children early. In view of the fact that several prenatal factors such as PA, smoking, dietary habits and not smoking are modifiable, health care professionals such as doctors, physicians, midwifes, teachers and persons involved in maternal and child healthcare and information should recommend prospective mothers and children to take care for their health choosing healthier dietary habits and a physically active lifestyle and avoiding overweight and smoking.

The most significant strengths of this study were: (a) it examined the possible association between numerous prenatal factors and PF components taking into account a large, representative sample equally distributed (about 500 dyads per year) throughout the study period (1997-2007); (b) a well-balanced sex distribution; and (c) an adjustment for several factors that possibly confound the association of the above factors with PF.

The information that was collected during the telephone interviews was self-reported. Consequently, although mothers could provide information derived from health records for themselves, this consists in a limitation of the study. Particularly, this could be attributed to deliberate over-reporting, underreporting, or recall bias for the self-reported prepregnancy data.

\section{Conclusions}

In summary, among Greek children 8 to 9 years old, we presented significant associations of parity before, educational level and PA and smoking during pregnancy with all PF components (CRF, lower and upper body strength and speed), after adjustment for several potential confounders.

\section{Acknowledgments}

The authors want to thank the study subjects for their willingness to participate. 


\section{References}

1. Ortega FB, Ruiz JR, Castillo MJ, Sjöström M. Physical fitness in childhood and adolescence: A powerful marker of health. International Journal of Obesity (Lond) 2008; 321(1):1-11.

2. Anderssen SA, Cooper AR, Riddoch C, et al. Low cardiorespiratory fitness is a strong predictor for clustering of cardiovascular disease risk factors in children independent of country, age and sex. European Journal of Cardiovascular Prevention \& Rehabilitation 2007; 14:526-31.

3. Montgomery H, Safari L. Genetic Basis of Physical Fitness. Ann Rev Anthropol 2007; 36(1):391-405.

4. Reynolds RM, Allan KM, Raja EA, et al. Maternal obesity during pregnancy and premature mortality from cardiovascular event in adult offspring: Follow-up of 1323275 person years. BMJ 2013; 347:f4539

5. Ferraro ZM, Contador F, Tawfiq A, Adamo KB, Gaudet L. Gestational weight gain and medical outcomes of pregnancy. Obstet Med 2015; 8(3):133-7.

6. Simeoni U, Barker DJ. Offspring of diabetic pregnancy: Long-term outcomes. Semin Fetal Neonatal Med 2009; 14:119-24.

7. Ferreira I, Peeters LL, Stehouwer CD. Preeclampsia and increased blood pressure in the offspring: Meta-analysis and critical review of the evidence. J Hypertens 2009; 27:1955-9.

8. Washburn L, Nixon P, Russell G, Snively BM, O'Shea TM. Adiposity in adolescent offspring born prematurely to mothers with preeclampsia. J Pediatr 2013; 162:912-7.e1.

9. Kajantie E, Eriksson JG, Osmond C, Thornburg $\mathrm{K}$, Barker DJ. Pre-eclampsia is associated with increased risk of stroke in the adult offspring: The Helsinki Birth Cohort Study. Stroke 2009; 40:1176-80.

10. Dior UP, Lawrence GM, Sitlani C, et al. Parental smoking during pregnancy and offspring cardio- metabolic risk factors at ages 17 and 32. Atherosclerosis 2014; 235:430-7.

11. Mamun AA, O'Callaghan MJ, Williams GM, Najman JM. Maternal smoking during pregnancy predicts adult offspring cardiovascular risk factors - evidence from a community-based large birth cohort study. PLoS One 2012; 7:e41106.

12. Horta BL, Gigante DP, Nazmi A, Silveira VMF, Oliveira I, Victora CG. Maternal smoking during pregnancy and risk factors for cardiovascular disease in adulthood. Atherosclerosis 2011; 219:815-20.

13. Centers for Disease Control and Prevention. Fetal Alcohol Spectrum Disorders (FASDs). https:// www.cdc.gov/ncbddd/fasd/alcohol-use.html. Assessed 20 Feb 2020.

14. Pirkle CM, de Albuquerque Sousa AC, Alvarado B, Zunzunegui MV; IMIAS Research Group. Early maternal age at first birth is associated with chronic diseases and poor physical performance in older age: cross-sectional analysis from the International Mobility in Aging Study. BMC Public Health 2014; 14:293.

15. Zer S, Wainstock T, Walfisch A, Sheiner E. Perinatal Outcomes and Long-term Health in Offspring of Teenage Mothers. J Pediatr Adolesc Gynecol 2019; 32(6):622-7. 16. Kajantie E, Hovi P. Is very preterm birth a risk factor for adult cardiometabolic disease? Semin Fetal Neonatal Med 2014; 19:112-7.

16. Kajantie E, Hovi P. Is very preterm birth a risk factor for adult cardiometabolic disease? Semin Fetal Neonatal Med 2014; 19:112-7.

17. Ferreira I, Gbatu PT, Boreham CA. Gestational Age and Cardiorespiratory Fitness in Individuals Born At Term: A Life Course Study. J Am Heart Assoc 2017; 6(10).

18. Lawlor DA, Cooper AR, Bain C, et al. Associations of birth sizeand duration of breast feeding with cardiorespiratory fitness inchildhood: Find- 
ings from the Avon Longitudinal Study of Parentsand Children (ALSPAC). Eur J Epidemiol 2008; 23:411-22.

19. Dodds R, Denison HJ, Ntani G, et al. Birth weight and muscle strength: A systematic review and meta-analysis. J Nutr Health Aging 2012; 16:609-15.

20. Li R, Scanlon KS, Serdula MK. The validity and reliability of maternal recall of breastfeeding practice. Nutrition Reviews 2005; 63(4):103-10.

21. World Health Organization (WHO). Preterm birth. https://www.who.int/news-room/fact-sheets/ detail/preterm-birth. Assessed 20 Feb 2020.

22. Council of Europe Committee of Experts on Sports Research. Eurofit: Handbook for the Eurofit Tests of Physical Fitness. Strasbourg: Council of Europe, Committee for the Development of Sport; (1993). p. 1-75.

23. Tambalis KD, Panagiotakos DB, Arnaoutis G, Sidossis LS. Endurance, explosive power and muscle strength in relation to Body Mass Index and physical fitness in Greek children aged 7 to 10-y-old. Pediatric Exercise Science 2013; 25(3):394-406.

24. Hagnäs MP, Cederberg H, Jokelainen J, Mikkola I, Rajala U, Keinänen-Kiukaanniemi S. Association of maternal smoking during pregnancy with aerobic fitness of offspring in young adulthood: a prospective cohort study. BJOG 2016; 123(11):1789-95.

25. Oken E, Levitan EB, Gillman MW. Maternal smoking during pregnancy and child overweight: sys- tematic review and meta analysis. Int J Obes (Lond) 2008; 32:201-10.

26. Mund M, Louwen F, Klingelhoefer D, Gerber A. Smoking and pregnancy-A review on the first major environmental risk factor of the unborn. Int J Environ Res Public Health 2013; 10:6485-99.

27. McMillan AG, May LE, Gaines GG, Isler C, Kuehn D. Effects of Aerobic Exercise during Pregnancy on 1-Month Infant Neuromotor Skills. Med Sci Sports Exerc 2019; 51(8):1671-6.

28. Lucovnik M, Starc G, Golja P, Verdenik I, Stucin Gantar I. Effects of Perinatal Factors on Body Mass Index and Physical Fitness of School-age Children. Zdr Varst 2018; 57(2):81-7.

29. Finger JD, Mensink GBM, Banzer W, Lampert T, Tylleskär T. Physical activity, aerobic fitness and parental socio-economic position among adolescents: the German Health Interview and Examination Survey for Children and Adolescents 20032006 (KiGGS). Int J Behav Nutr Phys Act 2014; 11:43.

30. Barclay K, Myrskylä M. Birth order and physical fitness in early adulthood: evidence from Swedish military conscription data. Soc Sci Med 2014; 123:141-8.
Received 27-05-20

Revised 05-06-20

Accepted 10-06-20 